\title{
NEONATAL OSTEOMYELITIS
}

\author{
C. J. M. KNUDSEN, E. B. HOFFMAN
}

From the Red Cross War Memorial Children's Hospital, Cape Town

Thirty-four neonates with osteomyelitis were reviewed. The hip (19) was the most common site involved.

Swelling and pseudoparalysis were the most significant local signs. Radiographic abnormalities, such as metaphyseal rarefaction and/or joint subluxation were found on the initial radiographs in 18 of the 19 hips involved.

All patients were treated with antibiotics and all infections involving joints were drained surgically. Good results were achieved in $75 \%$ of all sites and in $68 \%$ of hips.

Bone and joint sepsis in the first month of life is rare. The diagnosis is difficult and often delayed as the clinical features differ significantly from infections occurring in older children. In the post-antibiotic era, survival rates are high but the survivors are frequently left with permanent bone and joint damage. The hip is especially at risk.

We describe the clinical and radiographic features of the disease which facilitate early diagnosis and compare our long-term results with those reported in the literature.

\section{PATIENTS AND METHODS}

Between 1977 and 1987, 34 neonates ( $<28$ days old) were treated for osteomyelitis at the Red Cross War Memorial Children's Hospital, an average of three per year. Infection was confirmed by a positive blood culture, by the finding of pus at surgery or by radiographic changes such as metaphyseal rarefaction or periosteal reaction. The clinical records and radiographs of all these patients were analysed retrospectively and all were followed up as out-patients for at least 12 months. The average follow-up was 43 months (range 1 to 12 years).

Twenty-seven patients were reviewed personally by the authors. The other seven patients, not personally seen at review, were assessed by reference to their clinical records and radiographs.

C. J. M. Knudsen, FCS (SA) Orth, Orthopaedic Consultant E. B. Hoffman, FCS (SA) Orth, Orthopaedic Consultant Department of Orthopaedic Surgery, University of Cape Town and Red Cross War Memorial Children's Hospital, Rondebosch, Republic of South Africa.

Correspondence should be sent to Dr E. B. Hoffman at 7 Marne Avenue, Newlands, 7700, Cape Town, Republic of South Africa.

(C) 1990 British Editorial Society of Bone and Joint Surgery 0301-620X/90/5147\$2.00

J Bone Joint Surg [Br] 1990; 72-B :846-51.
Table I. Predisposing factors in 22 neonates

\begin{tabular}{ll}
\hline & Number \\
\hline Prematurity & 7 \\
$\begin{array}{l}\text { Skin/umbilical sepsis } \\
\begin{array}{l}\text { Delivered by Caesarian } \\
\text { section (1 premature) }\end{array}\end{array}$ & 7 \\
$\begin{array}{l}\text { Significant jaundice } \\
\text { (2 premature) }\end{array}$ & 4 \\
$\begin{array}{l}\text { Pneumonia } \\
\text { Meningitis }\end{array}$ & 2 \\
\hline
\end{tabular}

\section{FINDINGS}

Age at presentation. The average age at presentation was 23 days (range 8 to 28 ). None presented in the first week of life.

Predisposing factors. These were present in 22 patients $(65 \%)$ and are listed in Table I.

Clinical features. Based on the 'general' findings, two groups were identified. Group I consisted of 26 neonates who were not acutely ill at the time of presentation. Of these, 24 were apyrexial and two had only slight pyrexia. In 13 patients, the parents had not been alerted to the severity of the condition, which accounted for the delay in presentation which averaged 10 days.

Group II consisted of the remaining eight neonates who were acutely ill at initial presentation. Six were septicaemic and two had meningitis. In this group, attention was so focused on the systemic illness that the subtle local abnormalities were frequently overlooked. There was an average delay of five days before the diagnosis was made.

Subtle, local abnormalities were found in every case and are listed in Table II. The most frequent findings were swelling and pseudoparalysis (Fig. 1) which affected $95 \%$ of involved limbs. 


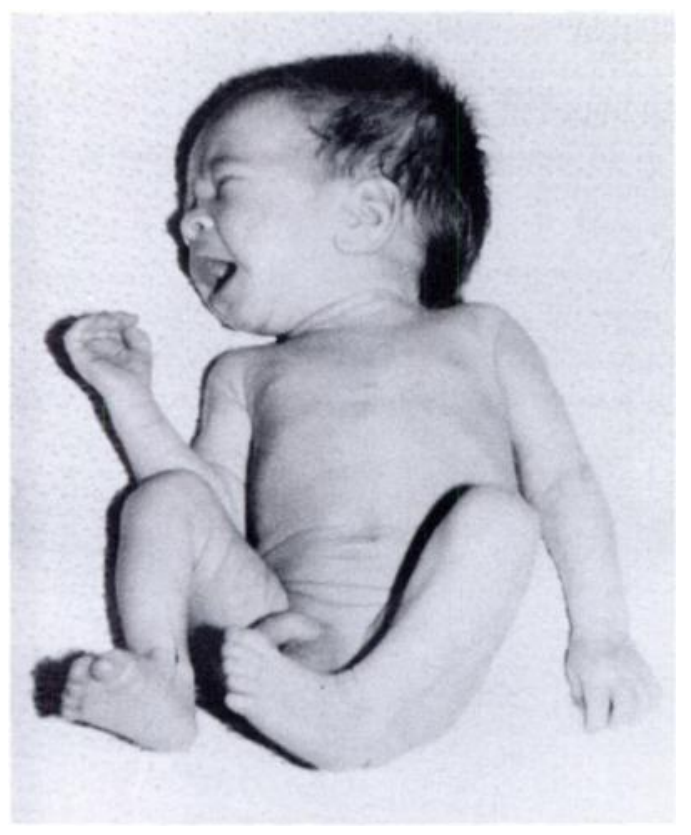

Fig. 1

Neonate with infection in the left proximal humerus/ shoulder and pseudoparalysis of the left arm.

Table II. Local abnormalities present in 34 neonates

\begin{tabular}{lc}
\hline Finding & Number* \\
\hline Pseudoparalysis & 26 \\
Local swelling & 25 \\
Pain on passive movement & 20 \\
Abnormal posture & 12 \\
\hline *at least one abnormality was detected in \\
every case, and 95\% of patients had either \\
pseudoparalysis and/or local swelling
\end{tabular}

Table III. Radiographic abnormalities noted at initial presentation of infection at different sites

\begin{tabular}{|c|c|c|}
\hline Sites & $\begin{array}{l}\text { Patients with } \\
\text { positive } \\
\text { findings }\end{array}$ & Findings \\
\hline Proximal femur/hip & 18 of 19 & $\begin{array}{l}14 \text { subluxed } \\
12 \text { metaphyseal rarefaction } \\
8 \text { both of the above }\end{array}$ \\
\hline $\begin{array}{l}\text { Proximal humerus/ } \\
\text { shoulder }\end{array}$ & 6 of 8 & $\begin{array}{l}4 \text { subluxed } \\
4 \text { metaphyseal rarefaction } \\
2 \text { both of the above }\end{array}$ \\
\hline Distal femur/knee & 4 of 6 & 4 metaphyseal rarefaction \\
\hline Proximal tibia & 5 of 5 & $\begin{array}{l}4 \text { metaphyseal rarefaction } \\
3 \text { periosteal reaction } \\
2 \text { both of the above }\end{array}$ \\
\hline Distal humerus & 1 of 1 & 1 metaphyseal rarefaction \\
\hline Olecranon/elbow & 1 of 2 & 1 metaphyseal rarefaction \\
\hline Calcaneum/subtalar & 1 of 1 & 1 metaphyseal rarefaction \\
\hline
\end{tabular}

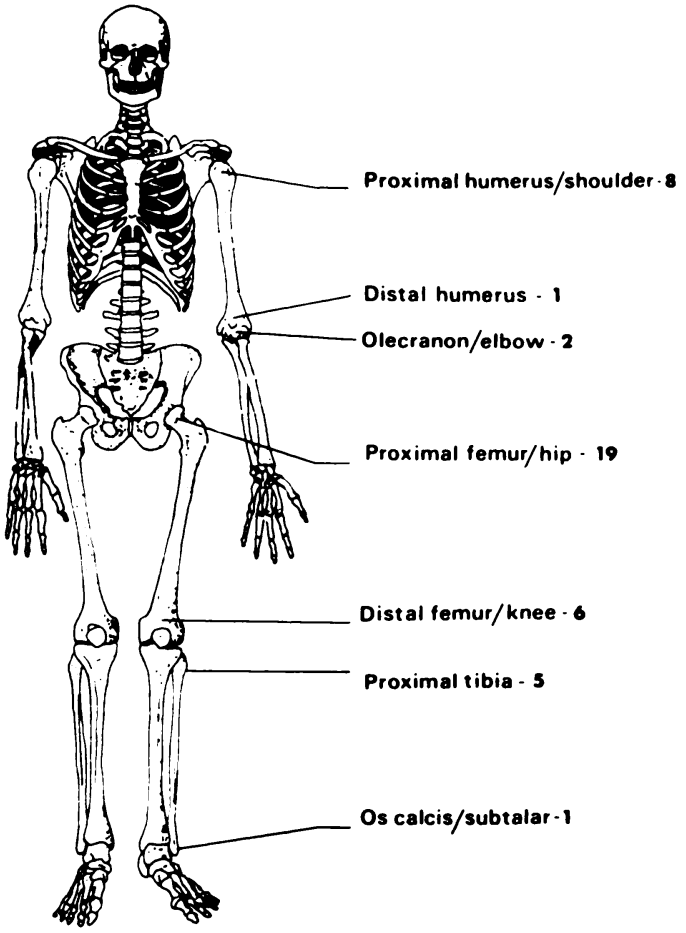

Fig. 2

Sites of sepsis in 34 neonates.

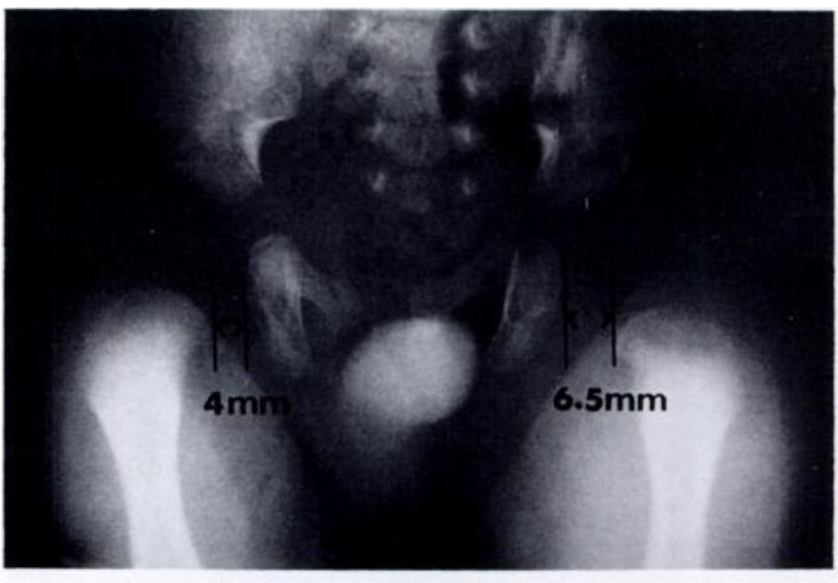

Fig. 3

Infection of the left proximal femur/hip. There is metaphyseal rarefaction of the proximal femur and a gap between the ischium and the proximal femur of more than $5 \mathrm{~mm}$.

Sites. There were 42 sites of infection in the 34 neonates, the most frequent being the hip (45\%). In six cases (18\%) multiple sites were involved (Fig. 2).

Radiographic changes. Abnormalities such as subluxation, metaphyseal rarefaction or periosteal reaction were noted on the initial radiographs of 34 of the 42 sites of infection ( $81 \%$ ) (Table III). Of the 19 hips, 18 were subluxed and/or showed metaphyseal changes in the proximal femur at presentation (Fig. 3). Subluxation of 
the hip was defined as a gap of greater than $5 \mathrm{~mm}$ between the proximal femur and ischium on an AP radiograph of the pelvis taken with the legs symmetrically placed (Bertol, Macnicol and Mitchell 1982).

Bacteriology. An organism was cultured from blood or pus in 25 patients $(74 \%)$. Staphylococcus aureus, the most common, was grown in 18 patients $(72 \%)$. $\beta$-haemolytic streptococcus, the only other infective agent, was cultured in seven patients $(28 \%)$. Of these, one patient had group $A$ and six had group B $\beta$-haemolytic streptococcal

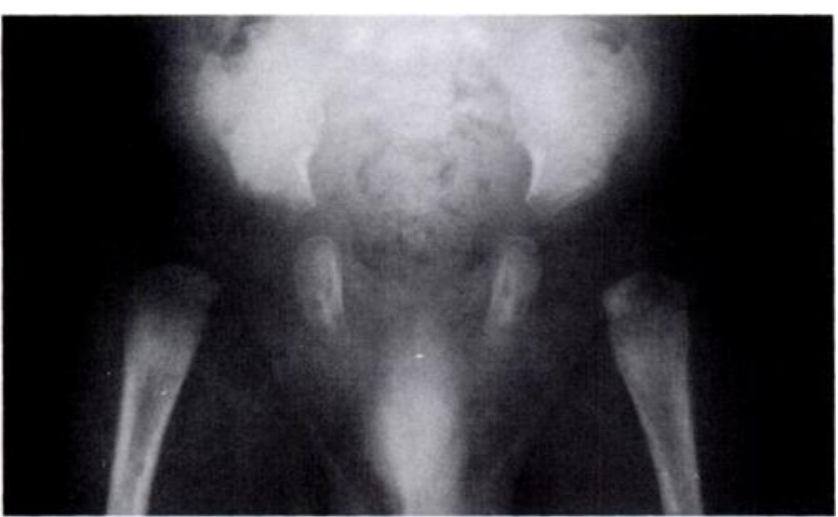

Fig. 4a infection. There were no gram-negative infections. Of the staphylococcal infections, five $(30 \%)$ were resistant to cloxacillin but sensitive to fucidic acid. These all occurred in premature neonates who had spent some time in hospital.

Management. All patients were admitted to hospital and treated with intravenous cloxacillin $(200 \mathrm{mg} / \mathrm{kg} /$ day $)$ for a minimum of 48 hours, following blood culture. Oral antibiotics were continued for six weeks. Initial antibiotic therapy was later adjusted according to the sensitivity

Figure 4a - Bilateral involvement of the proximal femur/hip, with bilateral subluxation and metaphyseal rarefaction of the proximal femur on the left. Pus was found at operation in both hips. Figure $4 \mathrm{~b}$ - Both hips showing excellent result at 46 months follow-up (Hallel and Salvati 1978, group I).

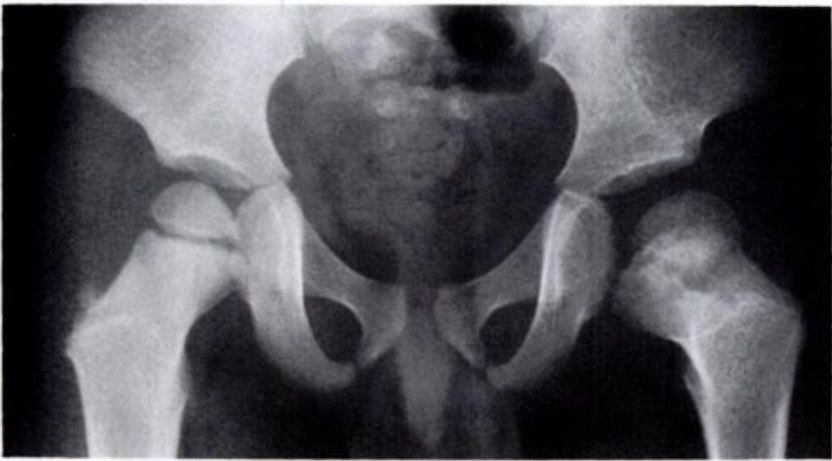

Fig. 5

Radiographs 50 months after infection of the left hip reveal varus of the left femoral neck (Hallel and Salvati 1978, group II).

Table IV. Outcome in 19 hips, using the classification of Hallel and Salvati (1978)

\begin{tabular}{lcl}
\hline $\begin{array}{l}\text { Number of } \\
\text { patients }\end{array}$ & Group & Findings \\
\hline 13 & I & $\begin{array}{l}\text { Normal capital epiphysis } \\
\text { or some loss of roundness }\end{array}$ \\
2 & II & $\begin{array}{l}\text { Deformed, small head, neck } \\
\text { in varus position }\end{array}$ \\
4 & III & Destroyed capital epiphysis \\
\hline
\end{tabular}

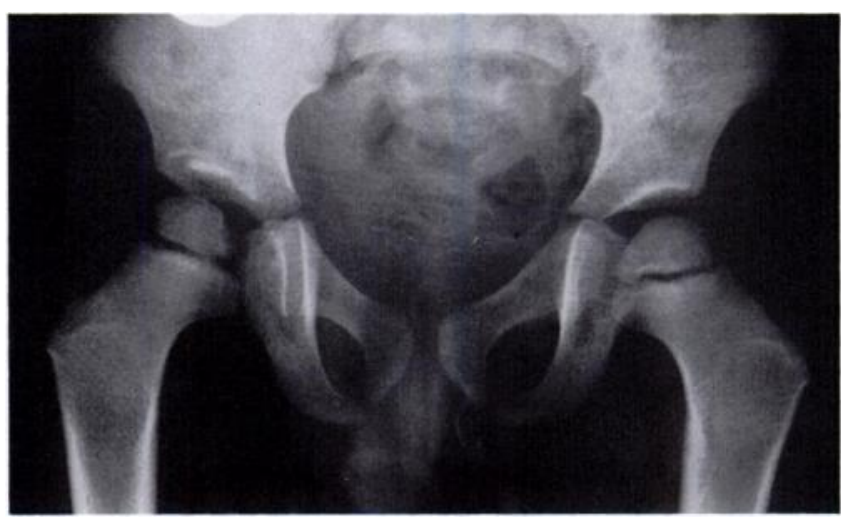

Fig. 4b 

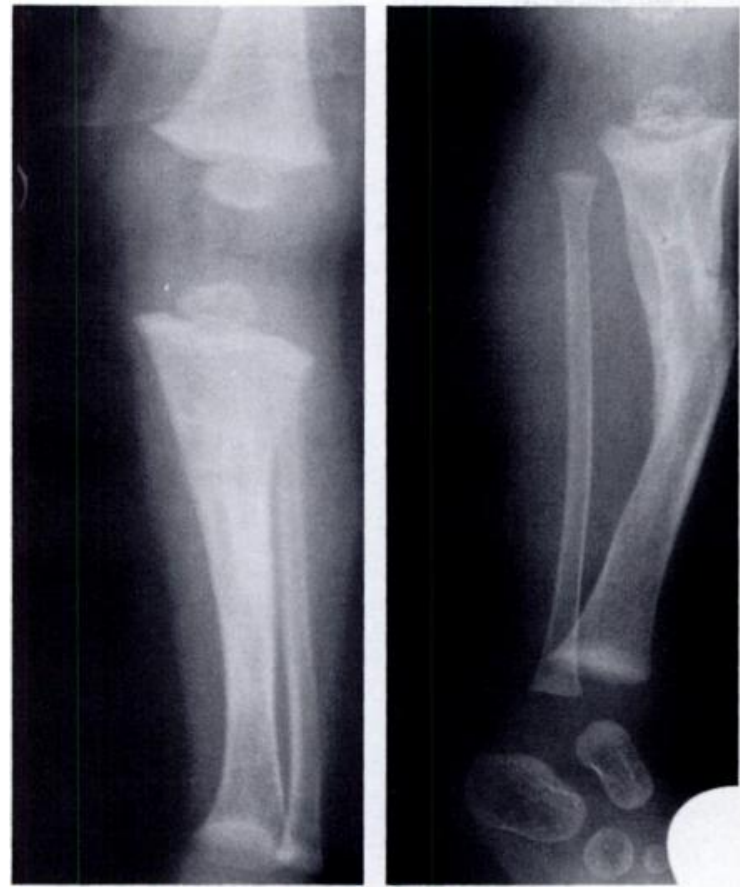

Fig. 7a
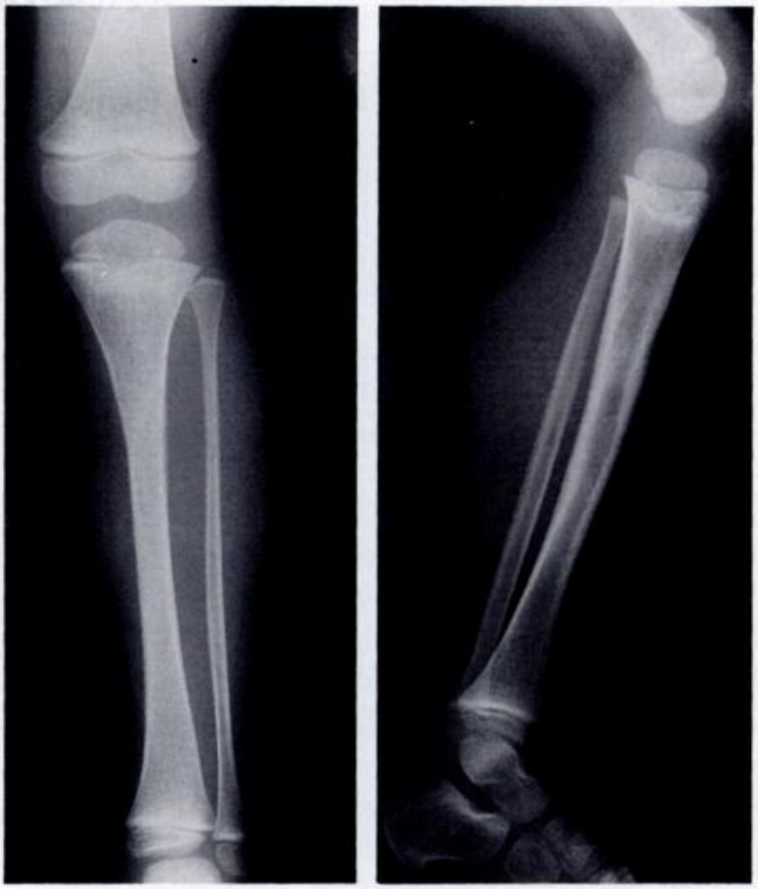

Fig. $7 b$

Figure $7 \mathrm{a}$ - Four months after osteomyelitis of the proximal tibia there is anterior bowing of the tibia. Figure $7 \mathrm{~b}-\mathrm{There}$ is complete restitution at follow-up 58 months later.

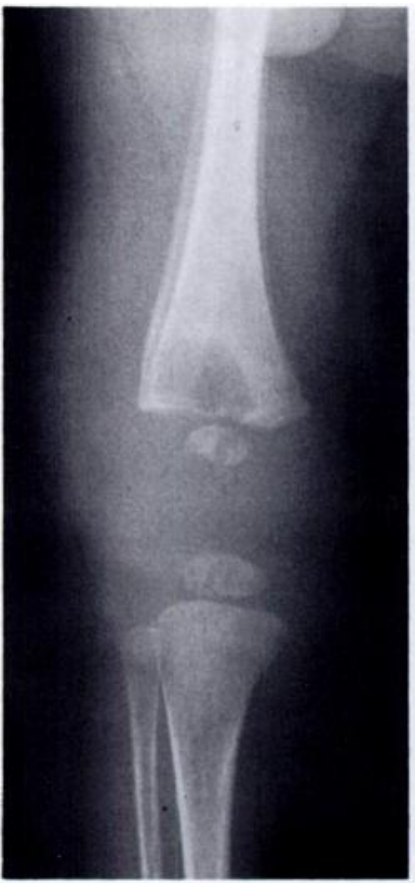

Fig. 8a

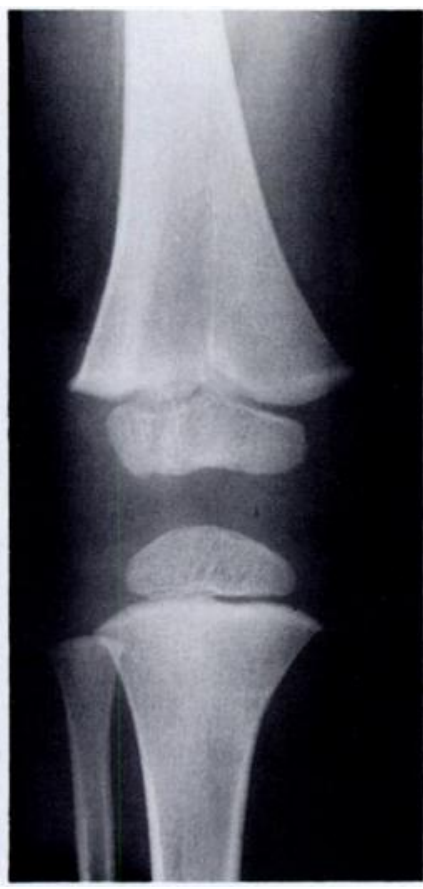

Fig. $8 \mathrm{~b}$
Figure 8a - Infection of the right distal femur/knee; pus was drained from the joint. Figure $8 b$ - Minimal metaphyseal changes at follow-up 39 months later.

The hip was always approached via an anterior Luck approach.

The 19 hips were splinted in abduction for an initial period of four weeks following drainage; $10(53 \%)$ were still dislocated at the end of the four-week period. These
Table V. Outcome at sites other than the hip

\begin{tabular}{|c|c|c|}
\hline Site & $\begin{array}{l}\text { Number } \\
\text { of patients }\end{array}$ & Findings \\
\hline Proximal humerus/shoulder & $\begin{array}{l}6 \\
2\end{array}$ & $\begin{array}{l}\text { Normal epiphysis/shoulder } \\
\text { Destroyed epiphysis }\end{array}$ \\
\hline Distal femur/knee & 6 & Normal femur/knee \\
\hline Proximal tibia & 5 & Normal tibia \\
\hline Olecranon/elbow & $\begin{array}{l}1 \\
1\end{array}$ & $\begin{array}{l}\text { Normal olecranon/elbow } \\
\text { Dislocated radial head }\end{array}$ \\
\hline Distal humerus & 1 & Normal humerus \\
\hline Os calcis/subtalar joint & 1 & Flat topped talus \\
\hline
\end{tabular}

were treated by abduction splintage for a further three months; six of them relocated and developed normal capital epiphyses; the four that remained dislocated all had destroyed capital epiphyses.

Outcome. There were no deaths in this series. The 19 affected hips were assessed using the classification of Hallel and Salvati (1978) and their long-term results are given in Table IV (see Figs 4 to 6). Thirteen hips (68\%) were assessed as excellent.

The fate of infections at all other sites is given in Table V. Of the shoulder infections, $75 \%$ resolved without sequelae. The two shoulders with destroyed epiphyses retained nearly full movements at follow-up. All infections of the distal femur and proximal tibia resolved completely with no leg length discrepancy, no angular deformities and normal or near normal epiphyses (Figs 7 and 8). 
Septic arthritis of the knee occurred in four of the six cases of distal femoral infection but in none of the cases of infection of the proximal tibia.

\section{DISCUSSION}

Greengard (1946) was the first to recognise two distinct clinical syndromes in neonatal osteomyelitis, a 'benign' form, where the child is not systemically ill, and a 'severe' form where the child is septicaemic and the osteomyelitis is an incident in the disease process. A similar grouping was found by Hutter (1948) and by Potter (1954). Thomson and Lewis (1950) and Dennison (1955) pointed out that the word 'benign' only relates to the clinical appearance of the child at presentation and is hardly a satisfactory description of a condition which may lead to permanent disability. Our findings support their opinion. In our patients who were systemically ill at presentation (group 2), all eight survived and five recovered without permanent bone or joint damage. Of the 26 children who were not systemically ill at presentation (group 1), five suffered permanent bone or joint damage.

The significance of the two groups is that there is often delay in diagnosis of the severely ill patients, as the attention of the doctor is not focused on the osteomyelitis. Diagnosis. The importance of early diagnosis has been emphasised by others (Obletz 1960; Lloyd-Roberts 1979). Isotope scanning is usually unreliable in the neonate (Ash and Gilday 1980; Bergdahl, Ekengren and Eriksson 1985), so diagnosis depends on the subtle local and radiographic abnormalities. We found, as did Blanche (1952), Obletz (1960) and Weissberg, Smith and Smith (1974), that swelling and pseudoparalysis (confirmed by pinching the involved limb) remained the most significant signs. Unlike the older child with joint sepsis, in whom the infected joint is held rigidly immobile, it is possible in the neonate and infant to obtain a reasonable range of passive movement, despite sepsis. It is essential that this should not be misinterpreted. The white cell count was not of any assistance in the diagnosis, but the sedimentation rate was helpful (average $72 \mathrm{~mm} / \mathrm{hr}$ Westergren).

Radiographic features were extremely helpful in confirming the diagnosis. Of the 19 infected hips, 18 showed lateral subluxation and/or metaphyseal rarefaction on the initial radiographs. This is unlike the older child in whom radiographic changes at presentation are the exception rather than the rule. Hutter (1948) was the first to describe lateral displacement of the hip, Obletz (1960) found this sign to be present in all cases and Bergdahl et al (1985) found it in most cases of hip sepsis. The early metaphyseal rarefaction in the neonate may be explained by the softer bone of this age group, while the lateral subluxation may be explained by distension of the capsule with pus. Lloyd-Roberts (1979) postulated that in the presence of a metaphyseal infection, the surrounding tissues, including the capsule may become lax and oedematous. The adductors and hip flexors develop reflex spasm and this combination could account for lateral subluxation of the hip in those cases where there is no pus in the joint.

We now regard lateral subluxation as such an important diagnostic clue that we suggest that every septicaemic neonate should have pelvic radiographs to exclude occult hip sepsis. In addition, it is our current practice to subject all neonates with osteomyelitis involving the lower limb to a routine pelvic radiograph, because the local signs in the hip may be masked by simultaneous sepsis at a distal site in the ipsilateral limb. Pathology. With the exception of one knee, all infected sites showed radiographic signs of primary osteomyelitis at presentation (metaphyseal rarefaction, periosteal reaction) or developed these changes subsequently. This is similar to the findings of Ogden and Lister (1975), confirming that osteomyelitis is the primary pathology and that joint sepsis developed secondarily.

Bacteriology. Obletz (1960), Weissberg et al (1974), Hallel and Salvati (1978) and Bergdahl et al (1985) all reported a predominance of staphylococcal infections. Of the 10 sites with bad results in our series (six hips, two shoulders, one elbow, and one subtalar joint), nine were due to staphylococcal infections and one was due to a Group A streptococcal infection. Bergdahl et al (1985) found no difference in the sequelae after infection by either organism.

Management and outcome. The dramatic decline in the mortality from neonatal osteomyelitis during the postantibiotic era is a reflection of the efficacy of antibiotics in the control of septicaemia. We believe that intravenous cloxacillin in high doses $(200 \mathrm{mg} / \mathrm{kg} /$ day $)$ is the best initial therapy, except for the premature baby who has been previously hospitalised. On the basis of our finding of a high incidence of cloxacillin-resistant bacteria in this selected group, we currently start their treatment with fucidic acid $(30 \mathrm{mg} / \mathrm{kg} /$ day).

We do not believe, as did Greengard (1946), Wilkinson (1952) and Nicholson (1960), that surgical drainage of pus should be limited. Antibiotics cannot replace surgical drainage. We concur with Blanche (1952), Obletz (1960) and Lloyd-Roberts (1979) that the hip should be decompressed by adequate open arthrotomy. Obletz (1960) aspirated the hip as a diagnostic procedure, but this has been shown by Paterson (1970) to be unreliable and is not recommended.

The outcome at sites other than the hip is shown in Table V. A favourable outcome of infections involving the tibia and femur/knee was reported by Trueta (1959) and by Lloyd-Roberts (1960). Angular deformities of the tibial shaft (Fig. 7a) corrected with time (Fig. 7b) and no patient developed chronic osteitis.

Involvement of the hip produces the most serious sequelae (Lloyd-Roberts 1960). Our series of 19 hips is the largest we could find in the literature. Previous authors have reported poor results ranging from $50 \%$ failure (Bergdahl et al 1985) to $80 \%$ (Hallel and Salvati 
1978). Our patients, with $68 \%$ excellent results, did significantly better. We believe our good results are due to adequate antibiotic dosage, immediate surgical drainage and appropriate splintage.

Obletz (1960) used splintage for a period varying between three weeks and 18 months. Lloyd-Roberts (1979) emphasised the importance of immobilising the hip in a stable position of abduction and some flexion. Of the 19 hips in our series, nine were clinically stable and radiographically located after four weeks of abduction splintage and all nine developed normally.

Ten hips ( $53 \%$ ) remained dislocated after four weeks of splintage and these were all treated by some form of abduction splint for a further three months. Of those, six subsequently became stable. The four that remained unstable were those in which the capital epiphysis had been destroyed. This finding is in accord with that of Hallel and Salvati (1978) who reported that dislocated hips with minimal or moderate femoral head destruction have a good chance of being reduced by conservative means within the first two months after infection. Failure to achieve a stable hip after three months of appropriate splintage is, we believe, highly suggestive of destruction of the capital epiphysis. Further splintage for more than three months after drainage is probably of little value.

Of the 10 bad results in this series, prematurity was the most common associated factor; all five having cloxacillin-resistant staphylococcal infections. Kuo et al (1975) have shown an immature immune response in premature babies.

Conclusions. We believe that the fate of the infected hip is not sealed from the outset. Awareness of this condition and a knowledge of the clinical and radiographic findings at presentation make early diagnosis possible. Adequate antibiotic therapy and immediate open drainage is the best method to preserve the femoral capital epiphysis. Splintage of the frankly dislocated hip should be continued for at least three months because a good result may be anticipated if the epiphysis is not destroyed.

We would like to thank Mr Martin Singer for his help in preparing the script, Vera Barrow for the typing and Michael Wyeth for the illustrations. This study was supported by a grant from the Medical Research Council of South Africa.

No benefits in any form have been received or will be received from a commercial party related directly or indirectly to the subject of this article.

\section{REFERENCES}

Ash JM, Gilday DL. The futility of bone scanning in neonatal osteomyelitis. J Nucl Med 1980; 21 :417-20.

Bergdahl S, Ekengren K, Eriksson M. Neonatal hematogenous osteomyelitis. J Pediatr Orthop 1985; 5:564-8.

Bertol P, Macnicol MF, Mitchell GP. Radiographic features of neonatal congenital dislocation of the hip. J Bone Joint Surg [Br] 1982; 64B:176-9.

Blanche DW. Osteomyelitis in infants. J Bone Joint Surg [Am] 1952; 34-A:71-85.

Dennison WM. Haematogenous osteitis in the newborn. Lancet 1955; ii :474-6.

Greengard J. Acute hematogenous osteomyelitis in infancy. M Clin North America 1946; 30:135-45.

Hallel T, Salvati EA. Septic arthritis of the hip in infancy: end result study. Clin Orthop 1978; 132:115-28.

Hutter CG Jr. New concepts of osteomyelitis in the newborn infant. $J$ Pediatr 1948; 32:522-9.

Kuo KN, Lloyd-Roberts GC, Orme IM, Soothill JF. Immunodeficiency and infantile bone and joint infection. Arch Dis Child 1975; 50: $51-6$.

Lloyd-Roberts GC. Suppurative arthritis of infancy. J Bone Joint Surg [Br] $1960 ; 42-B: 706-20$.
Lloyd-Roberts GC. Septic arthritis in infancy. Aust Paediatr J 1979; 15(Special Issue):41-3.

Nicholson JT. Discussion. In: Oblitz BE. Acute suppurative arthritis of the hip in the neonatal period. J Bone Joint Surg [Am] 1960; 42A $: 30$.

Obletz BE. Acute suppurative arthritis of the hip in neonatal period. $J$ Bone Joint Surg [Am] 1960; 42-A:23-30.

Ogden JA, Lister G. The pathology of neonatal osteomyelitis. Pediatrics $1975 ; 55: 474-8$.

Paterson DC. Acute suppurative arthritis in infancy and childhood. $J$ Bone Joint Surg [Br] 1970; 52-B:474-82.

Potter CMC. Osteomyelitis in the new-born. J Bone Joint Surg [Br] 1954; 36-B:578-83.

Thomson J, Lewis IC. Osteomyelitis in new-born. Arch Dis Child 1950; 25:273-9.

Trueta J. The three types of acute haematogenous osteomyelitis: a clinical and vascular study. J Bone Joint Surg [Br] 1959; 41-B: 671-80.

Weissberg ED, Smith AL, Smith DH. Clinical features of neonatal osteomyelitis. Pediatrics 1974; 53:505-10.

Wilkinson FR. Discussion. In: Blanche DW. Osteomyelitis in infants. J Bone Joint Surg [Am] 1952; 34-A :84-5. 